\title{
Prefrontal dysfunction in depressed patients performing a complex planning task: a study using positron emission tomography
}

\author{
R. ELLiOTT, ${ }^{1}$ S. C. BAKER, R. D. ROGERS, D. A. O’LEARY, E. S. PAYKEL, \\ C. D. FRITH, R. J. DOLAN AND B. J. SAHAKIAN \\ From the Wellcome Department of Cognitive Neurology, Institute of Neurology, MRC Cyclotron Unit, \\ Hammersmith Hospital, University College London and Royal Free Hospital School of Medicine, London; \\ and the Departments of Experimental Psychology and Psychiatry, University of Cambridge
}

\begin{abstract}
Introduction. Patients with unipolar depression show impaired performance on the Tower of London planning task. Positron emission tomography, which has previously identified resting state blood flow abnormalities in depression, was used to investigate neural activity associated with performance of this task in depressed patients and normal controls.
\end{abstract}

Methods. Six patients with unipolar depression and six matched controls were scanned while performing easy and hard Tower of London problems in a one-touch computerized paradigm and while performing a perceptuomotor control task.

Results. The patients in this study showed an expected task-related performance deficit compared with normal subjects. In normal subjects, the task engaged a network of prefrontal cortex, anterior cingulate, posterior cortical areas and subcortical structures including the striatum, thalamus and cerebellum. Depressed patients failed to show significant activation in the cingulate and striatum; activation in the other prefrontal and posterior cortical regions was significantly attenuated relative to controls. Crucially, patients also failed to show the normal augmentation of activation in the caudate nucleus, anterior cingulate and right prefrontal cortex associated with increasing task difficulty.

Conclusions. These findings provide evidence for cingulate, prefrontal and striatal dysfunction associated with impaired task performance in depression. The present results are consistent with a central role of cingulate dysfunction in depression as well as suggesting impaired frontostriatal function.

\section{INTRODUCTION}

Global impairment of cognitive function is an ubiquitous finding in depressive disorders (Weingartner et al. 1981; Roy-Byrne et al. 1986; Austin et al. 1992; Elliott et al. 1996) but a coherent theoretical account of the deficits has proved elusive. Some have argued that the cognitive deficits simply reflect motivational

${ }^{1}$ Address for correspondence: Dr R. Elliott, Wellcome Department of Cognitive Neurology, Institute of Neurology, 12 Queen Square, London WC1 3BG. impairments (e.g. Hockey et al. 1986) while others have denied this claim (e.g. Richards \& Ruff, 1989). One of the most influential theories argues that depressed patients show deficits in effortful but not automatic cognitive tasks (Hasher \& Zacks, 1979; Weingartner \& Silberman, 1982; Hartlage et al. 1993). However, this hypothesis has not always been empirically supported with several studies failing to find the predicted interaction between degree of cognitive effort and task performance (Golinkoff \& Sweeney, 1989; Elliott et al. 1996). 
The relation between cognitive dysfunction and underlying neurophysiological abnormalities has also proved elusive. Many of the tasks on which depressed patients are impaired are sensitive to frontal lobe damage (Brown et al. 1994; Beats et al. 1995; Elliott et al. 1996). Cognitive impairment on analogous tasks has been demonstrated in striatal disorders (Brown \& Marsden, 1988; Owen et al. 1992), which are associated with affective disturbance (Folstein $e t$ al. 1991). Clinical and neuropsychological features in common between depression and basal ganglia disorders have led to explicit hypotheses of frontostriatal pathophysiology in depression (Folstein et al. 1991; Robbins et al. 1992). However, such arguments based on analogy with neurological patients are inevitably indirect and open to criticism. Functional imaging provides an alternative approach to the investigation of the neural correlates of cognitive dysfunction.

Abnormalities of $\mathrm{rCBF}$ in resting patients have been reliably demonstrated in earlier PET studies of depression (Bench et al. 1992; Drevets et al. 1992) and these abnormalities have been related to cognitive dimensions of the disorder. In a subgroup of patients with severe global cognitive deficits, resting rCBF in the medial prefrontal cortex was found to be abnormal (Dolan et al. 1992). Furthermore, decreased medial prefrontal metabolism has been shown to be significantly correlated with a measure of global cognitive dysfunction (Bench et al. 1993). All the depressed patient groups in this series of studies showed rCBF abnormalities in the anterior cingulate cortex, while analogous resting changes in the anterior cingulate were found in a group of depressed Parkinsonian patients but not in a matched group of matched non-depressed patients (Ring et al. 1994). These data can be interpreted as suggesting anterior cingulate dysfunction in depression.

The majority of existing PET studies of depression have assessed $\mathrm{rCBF}$ changes in resting patients; the present study addresses $\mathrm{rCBF}$ in patients during cognitive performance. The task used is a version of the Tower of London task (Shallice, 1982). Performance of Tower of London tasks has been shown to depend on intact frontal cortices (Shallice, 1982; Owen et al. 1990, 1992). Functional imaging studies of normal volunteers performing the task have confirmed the importance of the frontal, and particularly prefrontal cortices (Andreasen et al. 1992; Morris et al. 1993; Baker et al. 1996). The version of the task used here has previously been reported in a PET investigation of normal volunteers by Baker et al. (1996). Performance on this task is also one of the most sensitive indices of cognitive impairment in depression (Elliott et al. 1996). There is preliminary evidence (Elliott et al. 1997) that impaired performance on this task represents a state rather than a trait abnormality. A longitudinal study of patients with unipolar depression showed that performance on a onetouch Tower of London task returned to control levels on clinical recovery. The present study aimed to determine the cognitive anatomy associated with performance of this task in depressed patients and the extent to which this differs from that seen in normal subjects. On the evidence described above, we hypothesized that performance in the depressed patients would be associated with neural abnormalities in the prefrontal cortices, particularly the anterior cingulate and striatal structures.

\section{METHOD}

\section{Subjects}

Six right-handed patients meeting DSM-IV criteria for unipolar depression were recruited from Addenbrooke's and Fulbourn Hospitals, Cambridge; four were out-patients and two were day-patients. Duration of illness was at least 12 months for all subjects. Five of the subjects were male and one was a postmenopausal female; the mean age of the subjects was 34.7 (range 21 to 48 ). The severity of their depression was assessed using the Hamilton Depression Scale (Ham-D, Hamilton, 1960) and the Montgomery-Åsberg Depression Rating Scale (MADRS, Montgomery \& Åsberg, 1979). The mean scores were 23.8 (range 20 to 29) on the Ham-D and 35.3 (range to 39) on the MADRS. One of the patients was unmedicated, one was taking $20 \mathrm{mg}$ paroxetine, one was taking $20 \mathrm{mg}$ citalopram, one was taking $175 \mathrm{mg}$ dothiepin, one was taking $200 \mathrm{mg}$ amitriptyline and $800 \mathrm{mg}$ lithium and one was taking $150 \mathrm{mg}$ imipramine, $1000 \mathrm{mg}$ lithium and $750 \mathrm{mg}$ moclobemide. Patients were excluded if they had any history of head injury, neurological disorder or 
substance abuse of if they had been treated with ECT.

The control volunteers are those scanned by Baker et al. (1996). They were not rescanned but the raw scan data from these subjects were reanalysed in a new between subjects design. These six right-handed control volunteers (five male, one female) matched the patients for age (age range 18-55; mean 31.0) and educational attainment. Pre-morbid IQs were not available for these subjects but all patients and controls had school leaving ages of 16 or higher. Five controls and three patients were educated to degree level. The study was approved by the both the Hammersmith Hospital and the Addenbrooke's Hospital Local Research Ethics Committees and the Advisory Committee on the Administration of Radioactive Substances (ARSAC) UK. All patients and control subjects gave informed consent.

\section{PET scanning technique}

Regional cerebral blood flow was measured with a CTI model 953B PET Scanner (CTI, Knoxville, TN, USA), with the interplane septa retracted (Spinks et al. 1992). Following a 'slow bolus' infusion of $\mathrm{H}_{2}{ }^{15} \mathrm{O}$, integrated counts per pixel were performed during the $90 \mathrm{~s}$ acquisition frame, to provide an index of rCBF. Then $11.2 \mathrm{mCi}$ of $\mathrm{H}_{2}{ }^{15} \mathrm{O}$ was flushed with normal saline through a cannula into an antecubital vein over a period of $20 \mathrm{~s}$ at $10 \mathrm{ml} / \mathrm{min}$ by an automatic pump. Scanning commenced with detection of counts at the head, which began to rise after a constant delay and peaked between 30-40 s later in individual subjects. A total of 12 scans were performed repeated at 10 min intervals. Before each infusion a $30 \mathrm{~s}$ scan was acquired to correct for background activity. Correction for attenuation was made by performing a transmission scan with an exposed $68 \mathrm{Ge} / 68 \mathrm{Ga}$ external ring source before each session.

\section{Cognitive activation paradigm}

Subjects were scanned in the presence of low background noise and dimmed ambient lighting. Stimuli were presented on a Taxan SV-775EV touch-sensitive computer screen controlled by an IBM PS/2 microcomputer. The screen was mounted at a viewing distance of approximately $50 \mathrm{~cm}$ so that subjects could easily touch the bottom part of the screen with the index finger of the dominant hand, which rested on the chest between responses.

\section{Tower of London task}

This task has been fully described in previous papers (Owen et al. 1995; Baker et al. 1996). Briefly, two different arrays of three coloured balls were presented, one in the upper half of the screen and one in the lower half. At the bottom of the screen, the numbers $1,2,3,4,5$ and 6 appeared in $3 \mathrm{~cm}^{2}$ boxes comprising the response panel. On each trial subjects were required to work out the minimum number of moves needed to rearrange the lower set of balls to match the upper set. The number of moves required was indicated by touching the appropriate box in the response panel. The rules governing the movements of the balls were the same as for the original Tower of London task (Shallice, 1982) and were explained to the subjects in full during a practice session prior to scanning. Only one response per problem was permitted and no feedback was given during scans.

Subjects worked through a sequence of problems starting $90 \mathrm{~s}$ before the scan began. At the start of scanning, the sequence was advanced to a run of exclusively easy or difficult problems concealed within the sequence. Preliminary tests had shown that each of the hidden runs occupy the typical subject for between $30-40 \mathrm{~s}$. All the sequences of problems had the same distribution of $1,2,3,4,5$ and 6 moves. Within the concealed runs easy problems always required 2 or 3 moves to solve, difficult problems 4 or 5 moves, however, 1 and 6 move problems were never scanned. None of the subjects detected the hidden runs.

\section{Control task}

The yoked control task required subjects to monitor a display similar to that in the experimental task but with upper and lower arrays identical. After an interval matching the response latency of the corresponding test trial, one of the balls 'blinked' and subjects were required to respond to this by touching the response box 3 .

\section{Procedure}

Each subject was scanned six times while performing the experimental task (three scans in 
each of the easy and difficult conditions) and six times while performing the control task. Both tasks were explained in full and practiced prior to scanning.

\section{Scan analysis}

Scans from each subject were realigned using the first as a reference (Friston et al. 1995a) and subsequently transformed into a standard space (Friston et al. 1995a) corresponding to the stereotactic atlas of Talairach \& Tournoux (1988). The normalized images were smoothed with a $15 \mathrm{~mm}$ FWHM isotropic Gaussian kernel.

\section{Statistical analysis}

Data were analysed with Statistical Parametric Mapping (SPM95, Wellcome Department of Cognitive Neurology, London, UK; Friston et al. 1995b) implemented in Matlab (Mathworks Inc. Sherborne MA, USA). The design matrix for this study reflected a $2 \times 2 \times 2$ factorial design, with subject group (patients, controls) as one factor, task type (planning, control) as another and task difficulty (hard, easy) as the third. Contrasts were specified to allow the main effects of these factors and the interactions between them to be determined. Global activity obviously varies between subjects and so can be considered as a confounding covariate. The appropriate analysis is, therefore, an ANCOVA with global activity as a covariate of no interest. Effects at each and every voxel were estimated according to the general linear model (Friston $e t$ $a l .1995 b$ ). The effects of the different conditions on specific brain regions were compared using linear contrasts. The resulting set of voxel values for each contrast constitute a statistical parametric map of the $t$ statistic, $\operatorname{SPM}\{t\}$.

$\operatorname{SPM}\{t\}$ were transformed to the unit normal distribution (SPM $\{Z\}$ ). The resulting foci were then characterized in terms of spatial extent $(k)$ and peak height $(u)$. The significance of each focus was estimated using distributional approximations from the theory of Gaussian fields. This gives the probability that a region of the observed number of voxels or greater could occur by chance $[P(n \max >k)]$, or that the peak height observed could occur by chance $[P(n \max >u)]$ over the entire volume analysed. In the initial analysis of these data, the $\operatorname{SPM}\{Z\}$ was thresholded at 3.09, corresponding to $P<0.001$ uncorrected. This threshold is usually considered acceptable when assessing prespecified anatomical hypotheses (see final paragraph of Introduction) and we therefore quote uncorrected $P$ values throughout. In the subsequent analyses, explicit hypotheses were addressed; namely that activation of components of this network would differ between easy and hard conditions and between normal and depressed subjects. The comparisons were therefore constrained to voxels at which significant $\mathrm{rCBF}$ changes were present in the comparison between task and control conditions in normal subjects. This constraint was imposed by assessing conjunctions between contrasts; that is determining which voxels were significantly activated in both the contrast of interest and the overall comparison between task and control conditions. This procedure is more statistically rigorous and substantially lowers the uncorrected $P$ values associated with particular $\operatorname{SPM}\{Z\}$ thresholds such that thresholds as low as $Z=2 \cdot 0$ can correspond to $P<0.001$.

\section{RESULTS}

\section{Performance data}

The accuracy and latency of task performance in depressed patients and controls at the easy and hard levels of task difficulty are shown in Table 1.

Two-way analysis of variance (ANOVA) showed a significant main effect of subject group on performance accuracy $(F(1,10)=9 \cdot 6$, $P<0 \cdot 05)$, reflecting impairment in the depressed patients. There was also a significant group by task difficulty interaction $(F(1,10)=16 \cdot 8$, $P<0.001)$, reflecting greater impairment in depressed patients on the harder problems. For response latency, two-way ANOVA showed no

Table 1. Percentage correct and response times for easy and hard problems as performed by patients and controls

\begin{tabular}{|c|c|c|c|c|}
\hline & \multicolumn{2}{|c|}{ Patients } & \multicolumn{2}{|c|}{ Controls } \\
\hline & $\begin{array}{c}\text { Correct } \\
(\%)\end{array}$ & $\begin{array}{l}\text { Latency } \\
\text { (s) }\end{array}$ & $\begin{array}{c}\text { Correct } \\
(\%)\end{array}$ & $\begin{array}{l}\text { Latency } \\
\text { (s) }\end{array}$ \\
\hline Easy problems & $83 \cdot 2(8)^{*}$ & $7 \cdot 09$ (1) & $96 \cdot 4$ (4) & $5 \cdot 44(0 \cdot 5)$ \\
\hline Hard problems & $46 \cdot 5(6)$ & $13 \cdot 5(2)$ & $81 \cdot 0(7)$ & $14 \cdot 7(1 \cdot 5)$ \\
\hline
\end{tabular}

* Standard errors are shown in parentheses. 
(a)
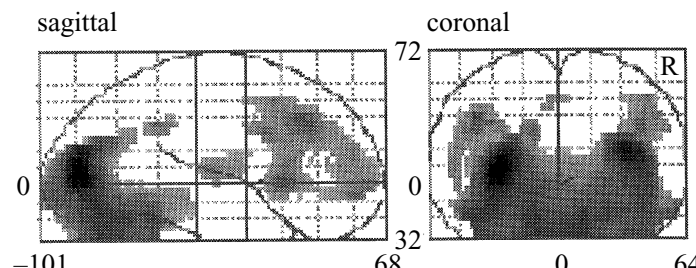

(b)
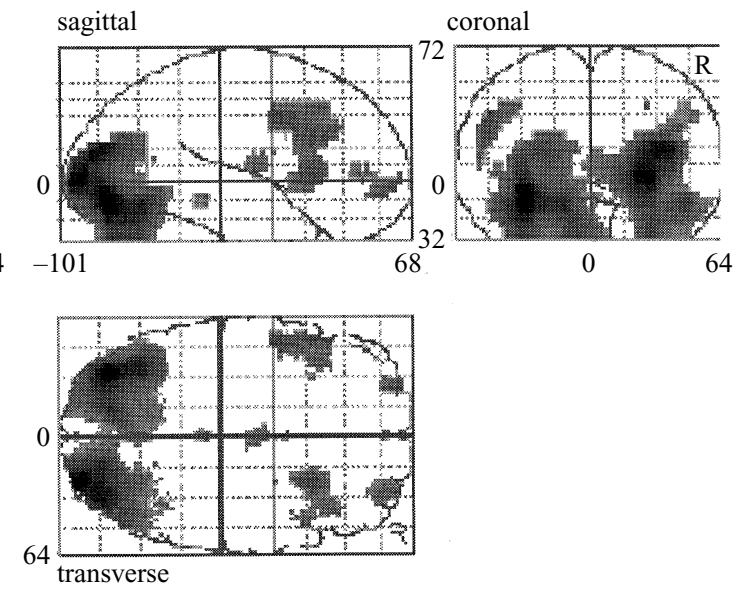

(c)
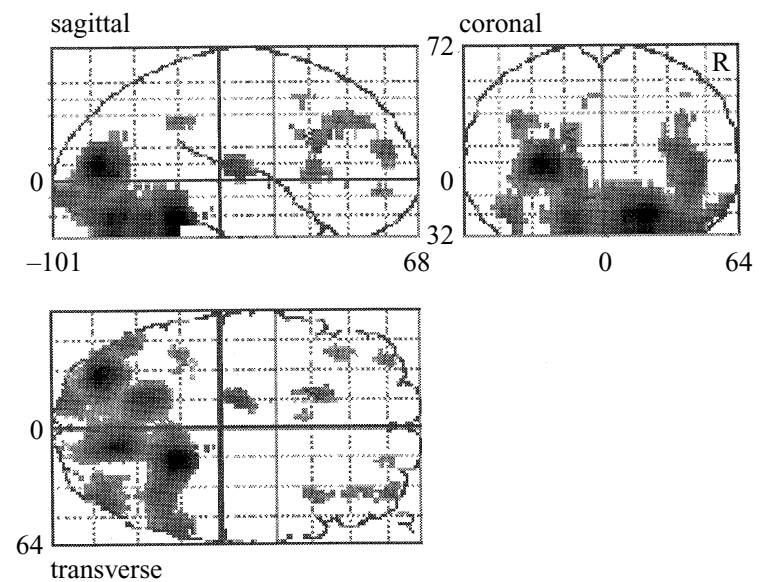

FIG. 1. Statistical parametric map of the $t$ statistic (after transformation to a $\operatorname{SPM}(Z)$ ) corresponding to the comparison of planning task with control task in normal subjects $(a)$ and depressed patients $(b)$, both thresholded at uncorrected $P<0 \cdot 001$. The quantitative comparison between the groups is shown in $(c)$, constrained to those voxels where there is greater activation in the planning than the control task and thresholded at $P<0 \cdot 001$. The SPMs are displayed as maximum intensity projections viewed from the right, the back and the top respectively, corresponding to the stereotactic atlas of Talairach \& Tournoux (1988).

significant effects. Depressed patients were no slower than normal subjects.

\section{Task related rCBF changes in normal subjects and depressed patients}

The pattern of activation observed in the normal subjects corresponded to that described previously (Baker et al. 1996). However, the most dorsal cortical areas engaged by the task in that study, including the lateral premotor cortex and precuneus, were not fully imaged in all subjects in the present group.
In normal subjects highly significant activation $(P<0.001)$ was observed in the frontal cortex (Fig. 1a; Table 2) including the dorsolateral and rostrolateral prefrontal cortices bilaterally (BA 9, 46, 10), the right anterior insula cortex, the left anterior cingulate gyrus (BA 24,32) and the medial premotor cortex (SMA; BA 6). Posterior cortical activation was observed bilaterally in the lateral occipital cortex (BA 19), lateral parietal cortex (BA 40) and in the depth of the right superior temporal sulcus (BA 39). More focal activations were also observed in 
Table 2. Coordinates of maximal significant changes of $r C B F$ between Tower of London and control conditions in normal subjects

\begin{tabular}{|c|c|c|c|c|c|c|}
\hline & \multicolumn{5}{|c|}{ Region of activation } & \multirow{2}{*}{$Z^{*}$} \\
\hline & Left/Right & $\begin{array}{l}\text { Brodmann's } \\
\text { area }\end{array}$ & \multicolumn{3}{|c|}{ Talairach coordinates } & \\
\hline \multicolumn{7}{|l|}{$\mathrm{rCBF}$ increases } \\
\hline Rostrolateral prefrontal cortex & $\mathrm{L}$ & 10 & -38 & 50 & 16 & $4 \cdot 21$ \\
\hline Dorsolateral prefrontal cortex & $\mathrm{R}$ & $9 / 46$ & 38 & 30 & 28 & $4 \cdot 74$ \\
\hline \multirow[t]{2}{*}{ Anterior cingulate cortex } & $\mathrm{L}$ & 24 & -14 & 8 & 28 & $4 \cdot 41$ \\
\hline & $\mathrm{L}$ & 24 & -16 & 20 & 24 & $3 \cdot 73$ \\
\hline \multirow[t]{2}{*}{ Anterior insula } & $\mathrm{R}$ & 45 & 28 & 18 & 0 & $5 \cdot 10$ \\
\hline & $\mathrm{R}$ & 45 & 34 & 14 & 4 & $4 \cdot 78$ \\
\hline Lateral occipital cortex & $\mathrm{L}$ & 19 & -30 & -84 & 8 & $9 \cdot 06$ \\
\hline Premotor cortex & $\mathrm{L}$ & 6 & -4 & 10 & 44 & $3 \cdot 89$ \\
\hline Caudate nucleus & $\mathrm{L}$ & - & -22 & 16 & 4 & $4 \cdot 28$ \\
\hline Rostral putamen & $\mathrm{R}$ & - & 22 & 12 & 0 & $4 \cdot 07$ \\
\hline \multirow[t]{2}{*}{ Cerebellum } & $\mathrm{L}$ & - & -2 & -72 & -28 & $6 \cdot 49$ \\
\hline & $\mathrm{R}$ & - & 12 & -76 & -20 & $6 \cdot 92$ \\
\hline \multirow[t]{2}{*}{ Thalamus } & $\mathrm{L}$ & - & -16 & -20 & 8 & $4 \cdot 16$ \\
\hline & $\mathrm{R}$ & - & 4 & -6 & 8 & $3 \cdot 53$ \\
\hline \multicolumn{7}{|l|}{ rCBF decreases } \\
\hline \multirow[t]{2}{*}{ Medial prefrontal cortex } & $\mathrm{L}$ & 10 & -14 & 54 & 24 & $5 \cdot 75$ \\
\hline & $\mathrm{R}$ & 10 & 4 & 50 & 0 & $4 \cdot 76$ \\
\hline \multirow[t]{2}{*}{ Superior temporal gyrus } & $\mathrm{L}$ & 22 & -44 & -20 & 8 & $7 \cdot 02$ \\
\hline & $\mathrm{R}$ & 22 & 46 & -14 & 4 & $8 \cdot 42$ \\
\hline Posterior cingulate & $\mathrm{R}$ & $24 / 31$ & 4 & -16 & 40 & $5 \cdot 04$ \\
\hline
\end{tabular}

subcortical structures, including the head of the caudate nucleus on the left and a right-sided activation extending from the insula with a focus in the rostral putamen. Highly significant rCBF decreases were observed in the medial prefrontal cortex, the superior temporal gyrus bilaterally and the posterior cingulate gyrus.

In an analogous analysis of task related $\mathrm{rCBF}$ changes in the depressed group (Fig. 1b; Table 3 ), activation was observed in corresponding structures with the exception of the anterior cingulate cortex, SMA and caudate nucleus. Activation in the inferior parietal cortices just failed to reach significance. The pattern of deactivation in the depressed group was also similar to the normal group.

\section{Quantitative differences between normal subjects and depressed patients}

In this comparison we used the statistically rigorous procedure of constraining the analysis to the subset of voxels where activations were seen in the overall comparison of planning and control tasks. The qualitative differences in activation profiles in the anterior cingulate cortex and caudate nucleus were shown to be highly significant by direct comparison of the task related $\mathrm{rCBF}$ changes in the normal and depressed groups $(P<0 \cdot 001)$. Activation throughout the dorsolateral and rostral prefrontal cortices was also significantly attenuated $(P<0.001)$ in the depressed patients compared to normal subjects. Similar attenuation of activation was also apparent in posterior cortical areas, thalamus and cerebellum in the depressed group (Table 4). rCBF decreases were also significantly attenuated in the medial prefrontal cortex, the superior and middle temporal gyri and the posterior cingulate gyrus.

\section{Comparison of hard and easy task conditions (within subject groups)}

In normal subjects a qualitatively similar network was activated in the easy and hard task 
Table 3. Coordinates of maximal significant changes of $r C B F$ between Tower of London and control conditions in depressed subjects

\begin{tabular}{|c|c|c|c|c|c|c|}
\hline & \multicolumn{5}{|c|}{ Region of activation } & \multirow[b]{3}{*}{$Z^{*}$} \\
\hline & \multirow[b]{2}{*}{ Left/Right } & \multirow{2}{*}{$\begin{array}{c}\text { Brodmann's } \\
\text { area }\end{array}$} & \multicolumn{3}{|c|}{ Talairach coordinates } & \\
\hline & & & $x$ & $y$ & $z$ & \\
\hline \multicolumn{7}{|l|}{$\mathrm{rCBF}$ increases } \\
\hline \multirow{2}{*}{ Rostrolateral prefrontal cortex } & $\mathrm{L}$ & 10 & -24 & 60 & 0 & $3 \cdot 43$ \\
\hline & $\mathrm{R}$ & 10 & 32 & 50 & 8 & $3 \cdot 27$ \\
\hline \multirow[t]{2}{*}{ Dorsolateral prefrontal cortex } & $\mathrm{L}$ & $9 / 46$ & -48 & 24 & 24 & $3 \cdot 16$ \\
\hline & $\mathrm{R}$ & $9 / 46$ & 42 & 26 & 28 & $3 \cdot 24$ \\
\hline Anterior insula & $\mathrm{R}$ & 45 & 26 & 18 & 4 & 3.77 \\
\hline \multirow[t]{2}{*}{ Lateral occipital cortex } & $\mathrm{L}$ & 19 & -30 & -84 & 8 & $5 \cdot 76$ \\
\hline & $\mathrm{R}$ & 19 & 26 & -94 & 4 & $5 \cdot 41$ \\
\hline Superior temporal cortex & $\mathrm{R}$ & 39 & 22 & -62 & 12 & $3 \cdot 22$ \\
\hline Rostral putamen & $\mathrm{R}$ & - & 22 & 12 & 0 & $3 \cdot 17$ \\
\hline \multirow{2}{*}{ Cerebellum } & $\mathrm{L}$ & - & -14 & -80 & -16 & $4 \cdot 53$ \\
\hline & $\mathrm{R}$ & - & 18 & -80 & -20 & 3.95 \\
\hline Thalamus & $\mathrm{R}$ & - & 4 & -10 & 8 & 3.09 \\
\hline \multicolumn{7}{|l|}{ rCBF decreases } \\
\hline \multirow[t]{2}{*}{ Medial prefrontal cortex } & $\mathrm{L}$ & 10 & -4 & 44 & 0 & $4 \cdot 02$ \\
\hline & $\mathrm{R}$ & 10 & 8 & 44 & 4 & 4.92 \\
\hline \multirow{2}{*}{ Superior temporal gyrus } & $\mathrm{R}$ & 22 & 50 & -16 & 4 & 5.98 \\
\hline & $\mathrm{L}$ & 22 & -44 & -12 & 8 & $5 \cdot 22$ \\
\hline Posterior cingulate & $\mathrm{R}$ & $24 / 31$ & 10 & -14 & 40 & 3.90 \\
\hline
\end{tabular}

* $Z=3.09$ for $P<0.001$

Table 4. Coordinates of maximal significant changes of $r C B F$ between Tower of London and control conditions in control compared to depressed subjects (i.e. areas that are more less strongly activated in depressed subjects). For this comparison, the analysis was constrained to those voxels where there were significant activations in the task-control comparison for the normal subjects. As a result, the probability levels associated with given $\mathrm{Z}$ scores are substantially reduced

\begin{tabular}{|c|c|c|c|c|c|c|}
\hline \multirow[b]{2}{*}{ Region of activation } & \multirow[b]{2}{*}{ Left/Right } & \multirow{2}{*}{$\begin{array}{l}\text { Brodmann's } \\
\text { area }\end{array}$} & \multicolumn{3}{|c|}{ Talairach coordinates } & \multirow[b]{2}{*}{$Z^{*}$} \\
\hline & & & $x$ & $y$ & $z$ & \\
\hline \multirow[t]{2}{*}{ Rostrolateral prefrontal cortex } & $\mathrm{R}$ & 10 & 40 & 52 & 12 & $2 \cdot 48$ \\
\hline & $\mathrm{L}$ & 10 & -38 & 50 & 16 & $2 \cdot 51$ \\
\hline Dorsolateral prefrontal cortex & $\mathrm{L}$ & $9 / 46$ & -42 & 30 & 32 & $2 \cdot 62$ \\
\hline Anterior insula & $\mathrm{R}$ & 45 & 40 & 16 & 4 & $2 \cdot 76$ \\
\hline \multirow[t]{2}{*}{ Lateral occipital cortex } & $\mathrm{L}$ & 19 & -30 & -84 & 8 & $5 \cdot 00$ \\
\hline & $\mathrm{R}$ & 19 & 44 & -80 & 4 & $3 \cdot 45$ \\
\hline Posterior visual cortex & $\mathrm{L}$ & 17 & -16 & -100 & -8 & 3.09 \\
\hline \multirow[t]{2}{*}{ Cerebellum } & $\mathrm{L}$ & - & -44 & -72 & -24 & 3.05 \\
\hline & $\mathrm{R}$ & - & 18 & -48 & -20 & $5 \cdot 05$ \\
\hline
\end{tabular}

* All of the activations are significant at $P<0.001$ level.

conditions. Quantitative comparison revealed significant differences in the extent of these activations. Performance of the hard condition compared to the easy condition was associated with increased activation in the bilateral dorso- lateral and rostrolateral prefrontal cortices, occipital cortices and cerebellum (see Table 5).

In depressed patients too, there was a qualitatively similar pattern of activation in the hard and easy conditions but again quantitative 
Table 5. Coordinates of maximal significant changes of $r C B F$ between easy and hard conditions of the Tower of London for: (i) normal controls; (ii) depressed patients; and (iii) quantitative comparisons between the two groups. For these comparisons, the analysis was constrained to those voxels where there were significant activations in the task-control comparison for the normal subjects. As a result, the probability levels associated with given $\mathrm{Z}$ scores are substantially reduced

\begin{tabular}{|c|c|c|c|c|c|c|}
\hline \multirow[b]{2}{*}{ Region of activation } & \multirow[b]{2}{*}{ Left/Right } & \multirow{2}{*}{$\begin{array}{l}\text { Brodmann's } \\
\text { area }\end{array}$} & \multicolumn{3}{|c|}{ Talairach coordinates } & \multirow[b]{2}{*}{$Z^{*}$} \\
\hline & & & $x$ & $y$ & $z$ & \\
\hline \multicolumn{7}{|l|}{ Normals } \\
\hline \multirow[t]{2}{*}{ Rostrolateral prefrontal cortex } & $\mathrm{R}$ & 10 & 34 & 50 & 16 & $3 \cdot 05$ \\
\hline & $\mathrm{L}$ & 10 & -36 & 50 & 16 & $2 \cdot 80$ \\
\hline \multirow[t]{2}{*}{ Dorsolateral prefrontal cortex } & $\mathrm{L}$ & $9 / 46$ & -42 & 30 & 32 & $2 \cdot 64$ \\
\hline & $\mathrm{R}$ & $9 / 46$ & 46 & 24 & 24 & $2 \cdot 50$ \\
\hline \multirow[t]{2}{*}{ Lateral occipital cortex } & $\mathrm{L}$ & 19 & -32 & -92 & 0 & $2 \cdot 92$ \\
\hline & $\mathrm{R}$ & 19 & 42 & -78 & 20 & $2 \cdot 62$ \\
\hline \multirow[t]{2}{*}{ Cerebellum } & $\mathrm{L}$ & - & -46 & -46 & -12 & $2 \cdot 51$ \\
\hline & $\mathrm{R}$ & - & 52 & -50 & -20 & $2 \cdot 62$ \\
\hline \multicolumn{7}{|l|}{ Depressed } \\
\hline \multirow[t]{2}{*}{ Dorsolateral prefrontal cortex } & $\mathrm{L}$ & $9 / 46$ & -36 & 20 & 36 & $3 \cdot 57$ \\
\hline & $\mathrm{R}$ & $9 / 46$ & 38 & 24 & 24 & $3 \cdot 12$ \\
\hline Medial occipital cortex & $\mathrm{R}$ & 18 & 8 & -100 & -8 & $2 \cdot 56$ \\
\hline Premotor cortex & $\mathrm{L}$ & 6 & -8 & 16 & 44 & $2 \cdot 49$ \\
\hline Cerebellum & $\mathrm{L}$ & - & -28 & -86 & -28 & $2 \cdot 25$ \\
\hline \multicolumn{7}{|l|}{ Normals-Depressed } \\
\hline Anterior cingulate & $\mathrm{L}$ & $32 / 24$ & -16 & 12 & 28 & $2 \cdot 39$ \\
\hline Caudate & $\mathrm{L}$ & - & -14 & 18 & -4 & $2 \cdot 48$ \\
\hline Rostral prefrontal cortex & $\mathrm{R}$ & 11 & 30 & 38 & -4 & $2 \cdot 36$ \\
\hline
\end{tabular}

* All of the activations are significant at $P<0.001$ level.

comparisons revealed significant differences. The hard condition was associated with greater activation in the bilateral dorsolateral prefrontal cortex, right occipital cortex, left cerebellum and left premotor cortex (see Table 5).

\section{Quantitative comparison of hard and easy task conditions (between subject groups)}

This comparison assessed the interaction between subject group and task difficulty. The normal subjects showed significantly greater difficulty-dependent augmentation of activation of the left anterior cingulate, left caudate and right prefrontal cortex (see Table 5). In contrast to normal subjects, depressed patients showed a relative decrease in $\mathrm{rCBF}$ in the anterior cingulate cortex in the hard condition.

\section{DISCUSSION}

In this study, depressed patients activated a similar neural network to controls during performance of a version of the Tower of London task. However, the patients differed from normal subjects in that they showed a significant attenuation of activation throughout the network of cortical and subcortical areas engaged by this cognitive task. A crucial finding, in the light of previous resting-state studies, was a specific failure in the depressed patients of taskrelated augmentation of activation in the anterior cingulate with increasing task difficulty; attenuation of task-related activation was also seen in the caudate nucleus and right rostrolateral prefrontal cortex.

\section{Neural systems engaged in planning}

The pattern of activation in normal subjects during performance of the Tower of London task has been described in a previous paper (Baker et al. 1996). We have suggested that the different regions of the activation pattern seen during performance of the Tower of London task study, including anterior cingulate, rostrolateral prefrontal cortex and coactivation of dorsolateral prefrontal cortex and posterior regions, reflect different component processes of the Tower of London planning task. As the task becomes more difficult, and these subprocesses 
are progressively taxed, normal subjects activate the network more strongly.

\section{Performance related activations in depressed patients}

One of the major findings of this study was the attenuation of activation seen in depressed patients throughout the network activated by the planning task. The two groups did not differ in terms of sensory input or motor output during scanning as performance latencies did not differ. Therefore, differing sensorimotor components do not confound these results. Performance accuracy did differ between the two groups, with patients showing pronounced deficits on the more difficult problems. These performance differences are not simply a function of motivational impairments in the patients since the response latencies increased monotonically as a function of task difficulty and were substantially longer than would be expected if subjects were guessing. Also, the pattern of activation was qualitatively similar to that seen in normal subjects which suggests they were attempting similar processing stages rather than guessing. Physiological data, discussed below, provides further compelling evidence that patients are increasingly engaged by more stringent task demands.

\section{Prefrontal dysfunction in depression}

Significant attenuation of activation in the depressed patient group in the dorsolateral prefrontal cortex and caudate nucleus in the easy condition is consistent with frontostriatal dysfunction underlying impairment on these problems. These two- and three-move problems can be solved relatively automatically and require little planning. The hard problems place a greater load on working memory, require conflict between subgoals to be resolved and are perceived as more effortful. In the normal group this was associated with augmented activation throughout the network engaged by the simple problems. In the depressed group activation in the hard conditions was attenuated in the anterior cingulate, caudate nucleus and rostral prefrontal cortex compared to normal subjects. However, the depressed group did show the expected augmentation of activation in the dorsolateral prefrontal cortex bilaterally. Im- pairment cannot therefore be attributed exclusively to generalized failure to activate, due for example, to poor motivation or non-specific effects of treatment.

In the original study of the Tower of London task (Shallice, 1982), performance was specifically impaired following lesions to the rostral prefrontal cortex. Performance deficits following rostral prefrontal lesions were confirmed in a subsequent investigation with equivalent impairment following left and right hemisphere lesions (Owen et al. 1990). Both neuropsychological and functional imaging studies suggest that the right rostral prefrontal cortex plays a significant role in response evaluation. Lesions in this region are associated with perseverative responding (Stuss et al. 1993), which has been interpreted as a failure of internal monitoring of responses. Activation in this area has been observed in a variety of simple and complex cognitive tasks, including monitoring for a single digit in a continuous performance task (Coull et al. 1996), a temporal ordering task (Petrides et al. 1993) and motor sequence learning (Jenkins et al. 1994). A common component of these tasks is a requirement for response evaluation; prefrontal activation was no longer apparent when a motor sequence had been learnt and could be executed automatically (Jenkins et al. 1994).

The failure of depressed patients to show augmented activation in the rostrolateral prefrontal cortex during performance of the hard problems may reflect their performance deficit on these problems. A failure to evaluate their responses adequately would contribute to impaired accuracy and it may also explain the fact that their response latencies are significantly shorter than those of control subjects, but only on incorrect trials.

\section{Striatal dysfunction in depression}

The prefrontal cortex projects topographically to the striatum, which in turn projects indirectly via the pallidum and thalamus to the same areas of prefrontal cortex forming a series of parallel corticostriatal loops (Alexander et al. 1986). Neuropsychological studies have demonstrated that striatal dysfunction in Parkinson's disease is associated with impaired performance on a variety of cognitive tasks sensitive to frontal 
lobe damage, including the Tower of London task (Owen et al. 1992, 1993). Although there are subtle differences in the nature of the cognitive impairment following striatal and prefrontal damage, functional impairment may follow pathophysiology at each level in a corticostriatal loop.

Functional imaging studies have demonstrated activation of the striatal structures in a variety of motor tasks (Brooks, 1995). In the present study, significant activation of the caudate nucleus was associated with task performance in the normal subjects. Activation of the caudate nucleus has also been described in the Tower of London task in a version in which subjects were required to make sequential moves (Owen et al. 1996). Augmentation of caudate activation associated with increasing task difficulty was not seen in the depressed patients. The abnormalities within reciprocally connected prefrontal and striatal structures seen in the present study are consistent with a fronto-striatal component to the pathophysiology of depression.

\section{Anterior cingulate dysfunction in depression}

The hypothesis that depression is associated with abnormal function of the cingulate cortex has been extensively discussed (George et al. 1993; Dolan et al. 1994). Depression has been associated specifically with reduced $\mathrm{rCBF}$ in the anterior cingulate and medial prefrontal cortex. In a cohort of depressed patients, decreased resting anterior cingulate $\mathrm{rCBF}$ was observed compared to normal subjects using PET (Bench et al. 1992). Furthermore, there was a positive correlation between impaired performance on attentional and mnemonic tests and decreased rCBF throughout the medial prefrontal and anterior cingulate cortex, extending to the ventral precommissural region of the cingulate gyrus (Dolan et al. 1994). Decreased resting rCBF in this ventral region has previously been observed in depression using SPECT and shown to increase with symptomatic recovery (Austin et al. 1992; Goodwin et al. 1993). In the present study, the focus of task related cingulate activation that was attenuated in the depressed group was caudal to the region of decreased resting $\mathrm{rCBF}$ in depression, indicating that cingulate dysfunction is more extensive than revealed by resting state studies. This suggests that medial prefrontal dysfunction in depression may be extensive and the focus of this dysfunction will depend on the conditions of the study; failure to respond to a cognitive challenge and resting state abnormality may represent different components of a more extensive abnormality.

Anatomically the anterior cingulate cortex extends around the head of the corpus callosum to the junction with the posterior cingulate cortex at the level of the central sulcus. Within this region several functional subdivisions can be recognized (Devinsky et al. 1995). The ventral region is interconnected with other limbic structures (Vogt \& Pandya, 1987; Konishio \& Haber, 1994) and projects to brainstem regions involved in autonomic control (Terreberry \& Neafsey, 1983; Hurley et al. 1991). This region plays an important role in affective responses. The dorsal cingulate cortex can be subdivided on the basis of its connections into a rostral cognitive division and a more caudal motor division, which has reciprocal connections with motor and premotor cortex and direct corticospinal projections (Dum \& Strick, 1991; Morecraft \& Van Hoesen, 1992).

Cingulate dysfunction provides a link between two important observations regarding the pathophysiology of depression, namely the association between basal ganglia disorders and affective disorders and the role of monoaminergic systems. Striatal pathophysiology may compromise function in corticostriatal loops that feed back to the orbital, cingulate and medial prefrontal cortex (Alexander et al. 1986). The medial cortical surface receives a rich monoaminergic innervation and is the site of dense dopamine and 5-HT receptor expression (Grasby et al. 1992). Lesions of the anterior cingulate cortex in man give rise to a syndrome characterized by reduced spontaneous thought and action, cardinal clinical features of depression. The evidence of cingulate dysfunction in this study and previous resting state studies (Bench et al. 1992; Dolan et al. 1994) supports a hypothesis that anterior cingulate dysfunction may constitute the fundamental cortical manifestation of depression.

\section{Posterior cortical dysfunction}

Strikingly, the most significant attenuations associated with depression were seen in posterior cortical areas, which could suggest that these 
regions are abnormal in depression. However, symptoms of posterior cortical dysfunction, primary sensory and visuospatial disorders, are not prominent features of depression and resting state studies do not implicate these areas in the pathophysiology of depression. The most parsimonious interpretation of this attenuation is that it represents functional sequelae of a primary prefrontal abnormality. Functional imaging studies have repeatedly demonstrated that posterior cortical areas, automatically activated in perceptual tasks, are coactivated with prefrontal cortex in cognitive tasks that involve active representation of information in working memory (Jonides et al. 1993; Baker et al. 1996). We consider, therefore, that the attenuation of activations within frontal and subcortical structures in depressed patients are of greater significance and that attenuations of posterior cortical areas may be a secondary consequence of frontostriatal attenuation.

\section{CONCLUSION}

The present study provides further evidence for striatal and anterior cingulate dysfunction in depression associated with more widespread impairment of prefrontal activity. The study also suggests an important striatal dysfunction under specific task conditions. These observations complement resting state rCBF studies which reveal both medial and lateral prefrontal hypoperfusion associated with anterior cingulate dysfunction. The central role of the caudal cingulate cortex in willed action and the intentional direction of attention parallels the impairment of spontaneous thought and action in depression. Abnormal patterns of activity in regions necessary for the performance of a task such as the Tower of London could lead to the failure to initiate and sustain mental activity seen in depression. The importance of studies in patients engaged in a cognitive task is their utility in ultimately establishing a coherent conceptual framework for relating clinical manifestations of depression to underlying neural substrates.

We acknowledge the support of the Wellcome Trust and the MRC Cyclotron Unit at the Hammersmith Hospital. This work was also funded by a Wellcome
Trust Programme Grant to Drs T. W. Robbins, B. J. Everitt, A. C. Roberts and B. J. Sahakian. R. Elliott was funded by a Wellcome Trust Prize Studentship.

\section{REFERENCES}

Alexander, G. E., DeLong, M. \& Strick, P. E. (1986). Parallel organization of functionally segregated circuits linking basal ganglia and cortex. Annual Review of Neuroscience 9, 357-381.

Andreasen, N. C., Rezai, K., Alliger, R., Swayze, V. W., Flaum, M., Kirchner, P., Cohen, G. \& O'Leary, D. S. (1992). Hypofrontality in neuroleptic-naive patients and in patients with chronic schizophrenia. Archives of General Psychiatry 49, 943-958.

Austin, M.-P., Dougall, N., Ross, M., Murray, C., O'Carroll, R. E., Moffoot, A., Ebmeier, K. P. \& Goodwin, G. M. (1992). Single photon emission tomography with $99 \mathrm{mTc}$-exametazime in major depression and the pattern of brain activity underlying the psychotic/neurotic continuum. Journal Affective Disorders 26, 31- 43.

Baker, S. C., Rogers, R. D., Owen, A. M., Frith, C. D., Dolan, R. J., Frackowiak, R. S. J. \& Robbins, T. W. (1996). Neural systems engaged by planning: a PET study of the Tower of London task. Neuropsychologia 6, 515-526.

Beats, B. C., Sahakian, B. J. \& Levy, R. (1995). Cognitive performance in tests sensitive to frontal lobe dysfunction in the elderly depressed. Psychological Medicine 26, 591-603.

Bench, C. J., Friston, K. J., Brown, R. G., Scott, L. C., Frackowiak, R. S. J. \& Dolan, R. J. (1992). The anatomy of melancholia - focal abnormalities of cerebral blood flow in major depression. Psychological Medicine 22, 607-615.

Bench, C. J., Friston, K. J., Brown, R. G., Frackowiak, R. S. J. \& Dolan, R. J. (1993). Regional cerebral blood flow in depression measured by positron emission tomography: the relationship with clinical dimensions. Psychological Medicine 23, 579-590.

Brooks, D. J. (1995). The role of the basal ganglia in motor control: contributions from PET. Journal of Neurological Science 128, $1-13$.

Brown, R. G. \& Marsden, C. D. (1988). 'Subcortical dementia': the neuropsychological evidence. Neuroscience 25, 363-387.

Brown, R. G., Scott, L. C., Bench, C. J. \& Dolan, R. J. (1994). Cognitive function in depression: its relationship to the presence and severity of intellectual decline. Psychological Medicine 24, $829-847$.

Coull, J. T., Frith, C. D., Frackowiak, R. S. J. \& Grasby, P. M. (1996). A fronto-parietal network for rapid visual information processing: a PET study of sustained attention and working memory. Neuropsychologia 34, 1085-1095.

Devinsky, O., Morrell, M. J. \& Vogt, B. A. (1995). Contributions of anterior cingulate cortex to behaviour. Brain 118, 279-306.

Dolan, R. J., Bench, C. J., Friston, K. J., Brown, R., Scott, L. \& Frackowiak, R. S. J. (1992). Regional cerebral blood flow abnormalities in depressed patients with cognitive impairment. Journal of Neurology, Neurosurgery and Psychiatry 55, 768-773.

Dolan, R. J., Bench, C. J., Brown, R. G., Scott, L. C. \& Frackowiak, R. S. J. (1994). Neuropsychological dysfunction in depression: the relationship to regional cerebral blood flow. Psychological Medicine 24, 849-857.

Drevets, W. C., Videen, T. O., Price, J. L., Preskorn, S. H., Carmichael, S. T. \& Raichle, M. E. (1992). A functional anatomical study of unipolar depression. Journal of Neuroscience 12, 3628-3641.

Dum, R. P. \& Strick, P. L. (1991). The origin of the corticospinal projections from the premotor areas in the frontal lobe. Journal of Neuroscience 11, 667-688.

Elliott, R., Sahakian, B. J., McKay, A. P., Herrod, J. J., Robbins, T. W. \& Paykel, E. S. (1996). Neuropsychological impairments in unipolar depression: the influence of perceived failure on subsequent performance. Psychological Medicine 26, 975-989. 
Folstein, F. E., Peyser, C. E., Starkstein, S. E. \& Folstein, M. F. (1991). Subcortical triad of Huntington's disease - a model for a neuropathology of depression, dementia and dyskinesia. In Psychopathology and the Brain (ed. B. J. Carroll and J. E. Barrett), pp. 65-75. Raven: New York.

Friston, K. J., Ashburner, J., Frith, C. D., Poline, J.-B., Heather, J. D. \& Frackowiak, R. S. J. (1995a). Spatial registration and normalisation. Human Brain Mapping 2, 1-25.

Friston, K. J., Holmes, A. P., Worsley, K. J., Poline, J.-B., Frith, C. D. \& Frackowiak, R. S. J. (1995b). Statistical parametric maps in functional imaging: a general approach. Human Brain Mapping 2, 189-210.

George, M. S., Ketter, T. A. \& Post, R. M. (1993). SPECT and PET in mood disorders. Journal of Clinical Psychiatry $\mathbf{5 4}$ (suppl.), 6-13.

Golinkoff, M. \& Sweeney, J. A. (1989). Cognitive impairment in depression. Journal of Affective Disorders 17, 105-112.

Goodwin, G. M., Austin, M.-P., Dougall, N., Ross, M., Murray, C., O'Carroll, R. E., Moffoot, A., Prentice, N. \& Ebmeier, K. P. (1993). State changes in brain activity shown by the uptake of $99 \mathrm{~m}$ Tc-exametazime with single photon emission tomography in major depression before and after treatment. Journal of Affective Disorders 29, 243-253.

Grasby, P. M., Friston, K. J., Bench, C., Cowen, P. J., Frith, C. D., Liddle, P. F., Frackowiak, R. S. J. \& Dolan, R. J. (1992). Effects of the 5-HT 1A partial agonist buspirone on regional cerebral blood flow in man. Psychopharmacology 108, 380-386.

Hamilton, M. (1960). A rating scale for depression. Journal of Neurology Neurosurgery and Psychiatry 23, 56-62.

Hartlage, S., Alloy, L. B., Vazquez, C. \& Dykman, B. (1993). Automatic and effortful processing in depression. Psychological Bulletin 113, 247-278.

Hasher, L. \& Zacks, R. T. (1979). Automatic and effortful proceses in memory. Journal of Experimental Psychology: General 108, 356-388.

Hockey, R. (1986). Stress and the cognitive components of skilled performance. In Human Stress and Cognition (ed. V. Hamilton and D. Warburton), pp. 141-178. Wiley: Chichester.

Hurley, K. M., Herbert, H., Moga, M. M. \& Saper, C. B. (1991). Efferent projections of the infralimbic cortex of the rat. Journal of Comparative Neurology, 308, 249-276.

Jenkins, I. H., Brooks, D. J., Nixon, P. D., Frackowiak, R. S. J. \& Passingham, R. E. (1994). Motor sequence learning: a study with positron emission tomography. Journal of Neuroscience 14, 3774-3790.

Jonides, J., Smith, E. E., Koeppe, R. A., Awh, E., Minoshima, S. \& Mintun, M. A. (1993). Spatial working memory in humans as revealed by PET. Nature 363, 623-625.

Kunishio, K. \& Haber, S. N. (1994). Primate cingulostriatal projection: limbic striatal vs. sensorimotor striatal input. Journal of Comparative Neurology 350, 337-356.

Montgomery, S. A. \& Àsberg, M. (1979). A new depression scale designed to be sensitive to change. British Journal of Psychiatry 134, 382-389.

Morecraft, R. J. \& Van Hoesen, G. W. (1992). Cingulate input to the primary and supplementary motor cortices in the rhesus monkey: evidence for somatotopy in areas $24 \mathrm{c}$ and 23c. Journal of Comparative Neurology 322, 471-489.

Morris, R. G., Ahmed, S., Syed, G. M. \& Toone, B. K. (1993). Neural correlates of planning ability: frontal lobe activation during the Tower of London test. Neuropsychologia 31, 1367-1378.

Owen, A. M., Downes, J. D., Sahakian, B. J., Polkey, C. E. \&
Robbins, T. W. (1990). Planning and spatial working memory following frontal lobe lesions in man. Neuropsychologia 28, 1021-1034.

Owen, A. M., James, M., Leigh, P. N., Summers, B. A., Marsden, C. D., Quinn, N. P., Sahakian, B. J. \& Robbins, T. W. (1992). Frontostriatal cognitive deficits at different stages of Parkinson's disease. Brain 115, 1727-1751.

Owen, A. M., Roberts, A. C., Hodges, J. R., Summers, B. A., Polkey, C. E. \& Robbins, T. W. (1993). Contrasting mechanisms of attentional set-shifting in patients with frontal lobe damage or Parkinson's disease. Brain 116, 1159-1175.

Owen, A. M., Sahakian, B. J., Hodges, J. R., Summers, B. A., Polkey, C. E. \& Robbins, T. W. (1995). Dopamine-dependent frontostriatal planning deficits in early Parkinson's disease. Neuropsychology 9, 126-140.

Owen, A. M., Doyon, J., Petrides, M. \& Evans, A. C. (1996) Planning and spatial working memory: a positron emission study in humans. European Journal of Neuroscience 8, 353-364.

Petrides, M., Alivisatos, B., Evans, A. C. \& Meyer, E. (1993). Dissociation of human mid-dorsolateral from posterior dorsolateral frontal cortex in memory processing. Proceedings of the National Academy of Science USA 90, 873-877.

Richards, P. M. \& Ruff, R. M. (1989). Motivational effects on neuropsychological functioning: comparison of depressed v. non depressed individuals. Journal of Consulting and Clinical Psychiatry 57, 396-402.

Ring, H. A., Bench, C. J., Trimble, M. R., Brooks, D. J., Frackowiak, R. S. J. \& Dolan, R. J. (1994). Depression in Parkinson's disease: a positron emission study. British Journal of Psychiatry 165, 333-339.

Robbins, T. W., Joyce, E. M. \& Sahakian, B. J. (1992). Neuropsychology and neuroimaging of affective disorders. In Handbook of Affective Disorders (ed. E. S. Paykel, pp. 289-309. Churchill Livingstone: London.

Roy-Byrne, P. P., Weingartner, H., Bierer, L. M., Thompson, K. \& Post, R. M. (1986). Effortful and automatic cognitive processes in depression. Archives of General Psychiatry 43, 265-267.

Shallice, T. (1982). Specific impairments in planning. Philosophical Transactions of the Royal Society of London B98, 199-209.

Spinks, T. J., Jones, T., Bailey, D. L., Townsend, D. W., Grootoonk, S., Bloomfield, P. M., Gilardi, M. C., Casey, M. E., Sipe, B. \& Reed, J. (1992). Physical performance of a positron tomograph for brain imaging with retractable septa. Physics in Medicine and Biology 37, 1637-1655.

Stuss, D. T., Alexander, M.-P. \& Palumbo, C. (1993). Word list learning in patients with frontal lobe lesions. Society for Neurosciences Abstracts 19, 409.7.

Talairach, J. \& Tournoux, P. (1988). Coplanar Stereotactic Atlas of the Human Brain. George Thieme Verlag: Stuttgart.

Terreberry, R. R. \& Neafsey, E. J. (1983). Rat medial frontal cortex: a visceral motor region with direct projection to a solitary nucleus. Brain Research 278, 245-249.

Vogt, B. A. \& Pandya, D. N. (1987). Cingulate cortex of the rhesus monkey: II Cortical afferents. Journal of Comparative Neurology 262, 271-289.

Weingartner, H. \& Silberman, E. (1982). Models of cognitive impairment: cognitive changes in depression. Psychopharmacological Bulletin 18, 27-42.

Weingartner, H., Cohen, R. M., Martello, J. Di \& Gerdt, C. (1981). Cognitive processes in depression. Archives of General Psychiatry 38, $42-47$. 